\title{
Pathology of ulcerative mycosis in Atlantic menhaden Brevoortia tyrannus
}

\author{
Edward J. Noga ${ }^{1}$, Jay F. Levine ${ }^{2}$, Michael J. Dykstra ${ }^{2}$, Jess H. Hawkins ${ }^{3}$ \\ ${ }^{1}$ Dept of Companion Animal and Special Species Medicine, and ${ }^{2}$ Dept of Microbiology, Pathology, and Parasitology, \\ College of Veterinary Medicine, North Carolina State University, Raleigh, North Carolina 27606, USA \\ ${ }^{3}$ North Carolina Division of Marine Fisheries, PO Box 1507, Washington, North Caralina 27889, USA
}

\begin{abstract}
The pathology of ulcerative mycosis in naturally affected Atlantic menhaden Brevoortia tyrannus is described. Ulcerative mycosis is a deep granulomatous dermatopathy caused by infection with oomycete fungi. The response to this fungal infection was similar to that described for other granulomatous diseases. The posteroventral portion of the body was most frequently affected, with $67 \%$ of all lesions observed in this area. Lesions appeared to begin as small, focal infections on or near the skin surface which rapidly enlarged and often extended into adjacent viscera. In many fish, this necrotic mass of tissue was sloughed, leaving a crater-shaped ulcer. Only fish with small ulcers had any evidence of healing, suggesting that this disease may cause high mortalities in affected populations.
\end{abstract}

\section{INTRODUCTION}

Ulcerative mycosis (UM) is a recently described dermatological disease that affects a number of important estuarine fishes along the Atlantic coast of the United States. It first became a serious problem in about 1984 when Atlantic menhaden Brevoortia tyrannus were observed with deep necrotic ulcers in several estuarine systems in North Carolina, including those of Pamlico and Albemarle Sounds (Noga \& Dykstra 1986). Other species were soon observed with UM. (Noga \& Dykstra 1986), and lesions resembling UM were soon reported to occur on fish from Chesapeake Bay (Hargis 1985) and the St Johns River estuary in Florida (Grier \& Quintero 1987). Since its appearance 4 yr ago, UM has continued to cause repeated disease outbreaks in these estuarine systems. Its continued presence has prompted increasing concern about the impact of the disease on the productivity of the estuarine fisheries.

Ulcerative mycosis is a granulomatous disease associated with infection by oomycete fungi. Aphanomyces has been most commonly cultured from UM lesions, but Saprolegnia has also been isolated (Dykstra et al. 1986). More than one species in these genera is probably involved. In our initial description of the disease, we provided preliminary information on the pathology of UM (Noga \& Dykstra 1986). The purpose of this article is to provide a detailed description of the ontogeny of UM lesions from naturally affected menhaden so that it can be differentiated from other dermatopathies affecting menhaden.

\section{MATERIALS AND METHODS}

Atlantic menhaden with skin lesions were collected primarily from pound nets set on the Pamlico River from July 1984 through July 1986. Fish were also obtained from trawl samples collected by the Division of Marine Fisheries and local fishermen in the Albemarle Sound, Pamlico River, Neuse River, and New River (N Carolina, USA).

All fish were alive at the time of capture and were necropsied on site. Gross appearance and size of the lesions were recorded. For light microscopy, tissues were fixed in either $10 \%$ neutral-buffered formalin or in Bouin's fluid. Skin, gills, stomach, intestine, pancreas, liver, spleen, heart, muscle, and brain were examined. All sections were embedded in paraffin and stained with hematoxylin and eosin ( $\mathrm{H} \& \mathrm{E}$ ). Selected tissues were also stained with Gomori methenamine silver (GMS), periodic acid Schiff (PAS), Giemsa (G), Brown and Brenn Gram's stain (B \& B), MacCollumGoodpasture Gram's stain (MG), Fite-Faraco acid-fast stain (FF) or Mallory's trichrome stain (T). 
For electron microscopy, tissues were fixed in McDowell's and Trump's fixative (McDowell \& Trump 1976), post-fixed in $1 \% \mathrm{OsO}_{4}$ in $0.1 \mathrm{M}$ phosphate buffer, $\mathrm{pH} 7.2$, dehydrated through a graded alcohol series, passed through acetone, and embedded in Spurr's resin. Sections were cut, stained with methanolic uranyl acetate and lead citrate, and examined with a transmission electron microscope.

Lesion size and location were also recorded on a randomly selected group of menhaden obtained by trawling in the Pamlico River in order to document the site of the infection on various parts of the body. Lesion size and area were calculated by measuring the widest and narrowest part of each lesion. Location was then recorded on a figure that subdivided the fish into 5 zones (Fig. i). Andiumical landmans inciuded the opercular border, the lateral line, and arbitrarily defined distances between various fins. The presence of UM was confirmed using skin scrapings; we considered the presence of aseptate hyphae to be diagnostic.

\section{RESULTS}

\section{Lesion distribution}

Menhaden collected ranged from 68 to $188 \mathrm{~mm}$ fork length (median length $97 \mathrm{~mm}$ ). A total of 424 fish with UM was collected. All but 16 of these fish had only 1 lesion. Fifteen fish had 2 lesions and 1 fish had 3 lesions. While virtually any part of the body could be affected, the ventrum, near the anus, was by far the most common site for development of a lesion (Fig. 1); $67 \%$ of all lesions affected this general area (i.e. areas $A / B, B$, and $B / D)$. Lesions were rarely seen on the head or the fins.

The lesions ranged from 6 to $1250 \mathrm{~mm}^{2}$ in area $\left(\right.$ median $\left.=100 \mathrm{~mm}^{2}\right)$. Although the lesions were not square and invariably not circumscribed, this is probably a conservative estimate of area affected because in many lesions, considerable muscle tissue had sloughed.

\section{Lesion development}

Skin lesions from 47 fish were examined histologically. Complete necropsies were also performed on 20 fish. Five clinically normal fish obtained from the Pamlico River were used for comparison. Based upon the gross and histologic features of all lesions examined, we defined a series of developmental stages for ulcerative mycosis:

Early Type I lesion. This stage was the smallest grossly recognizable lesion; it was relatively uncommon. This lesion appeared as a flat, red or yellow-red area on the skin up to about $5 \mathrm{~mm}$ in diameter (Figs. $2 \mathrm{~A}$ and $3 \mathrm{~A}$ ). The inflammatory response consisted primarily of macrophages with some lymphocytes and occasionally eosinophilic granular cells. Staining with GMS revealed 7 to $12 \mu \mathrm{m}$, aseptate hyphae (Fig. 3B), often surrounded by small granulomas (Fig. 3E, F). The fungal infection appeared to originate in or near a scale pocket, and hyphae were most prevalent near the surface of the skin. Fungal invasion was associated with necrosis of skeletal muscle and myophagia (Fig. 3C). Multinucleated giant cells were seen in some lesions, usually close to eroding scales (Fig. 3D). One of these giant cells appeared to be engulfing a hypha. Gram's stains for bacteria were negative; FF, G, and PAS stains did not reveal other pathogens.

Early Type II lesion. Also relatively uncommon, this lesion type appeared as a raised, 15 to $20 \mathrm{~mm}$ smooth mass on the dorsum containing a small central area of scale loss. Histologically, there was a small ulcerated area in the center of the lesion; the remainder of the skin overlying the mass was intact. These lesions had

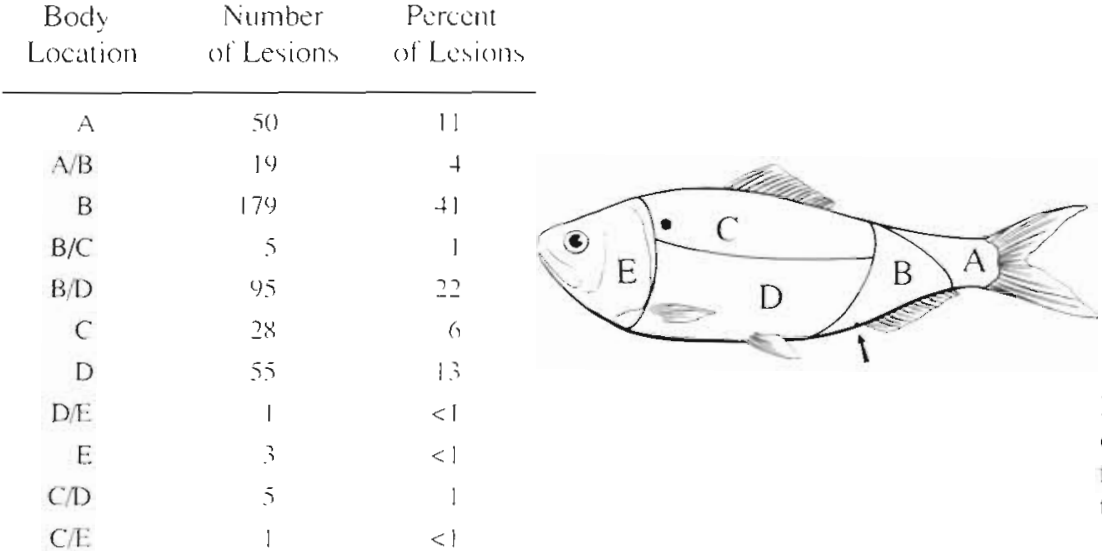

Fig. 1. Brevoortia tyrannus. Body distribution of ulcerative mycosis lesions on Atlantic menhaden. Combined sites (e.g. A/B) refer to lesions that overlapped both sites. Arrow indicates site of anus 

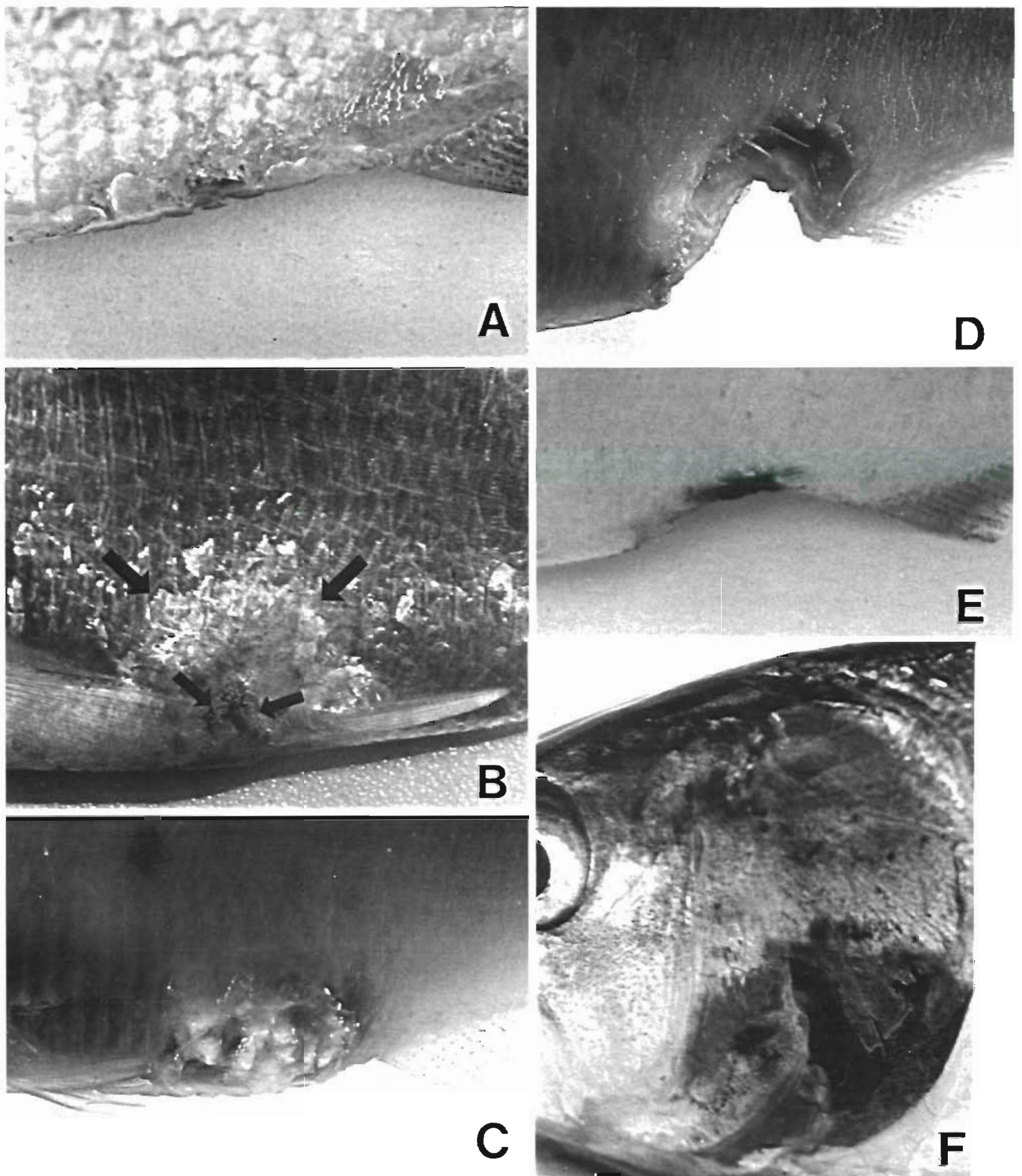

Fig. 2. Brevoortia tyrannus. Gross stages of ulcerative mycosis in Atlantic menhaden. All lesions are located near the anus unless specified otherwise. (A) Early Type I lesion. ( $\times 3.5$ ). (B) Mid-stage (between early and advanced) lesion on the ventrum. Note the central dark area of scale loss (small arrows) surrounded by a light zone of erosion and ulceration (large arrows). ( $\times 2.4$ ). (C) Advanced stage lesion. A large, white, edematous mass of friable necrotic muscle and hyphae fills the center of the lesion. $(x 2.0)$. (D) End-stage lesion. Note the deeply indented appearance. $(\times 2.0)$. (E) Healing lesion. Note the prominent notch, a sequela of tissue loss, and the hyperpigmented area where the peritoneal wall shows through. $(\times 2.0)$. $(F)$ Erosive osteomyelitis of the operculum. $(\times 2.8)$ 


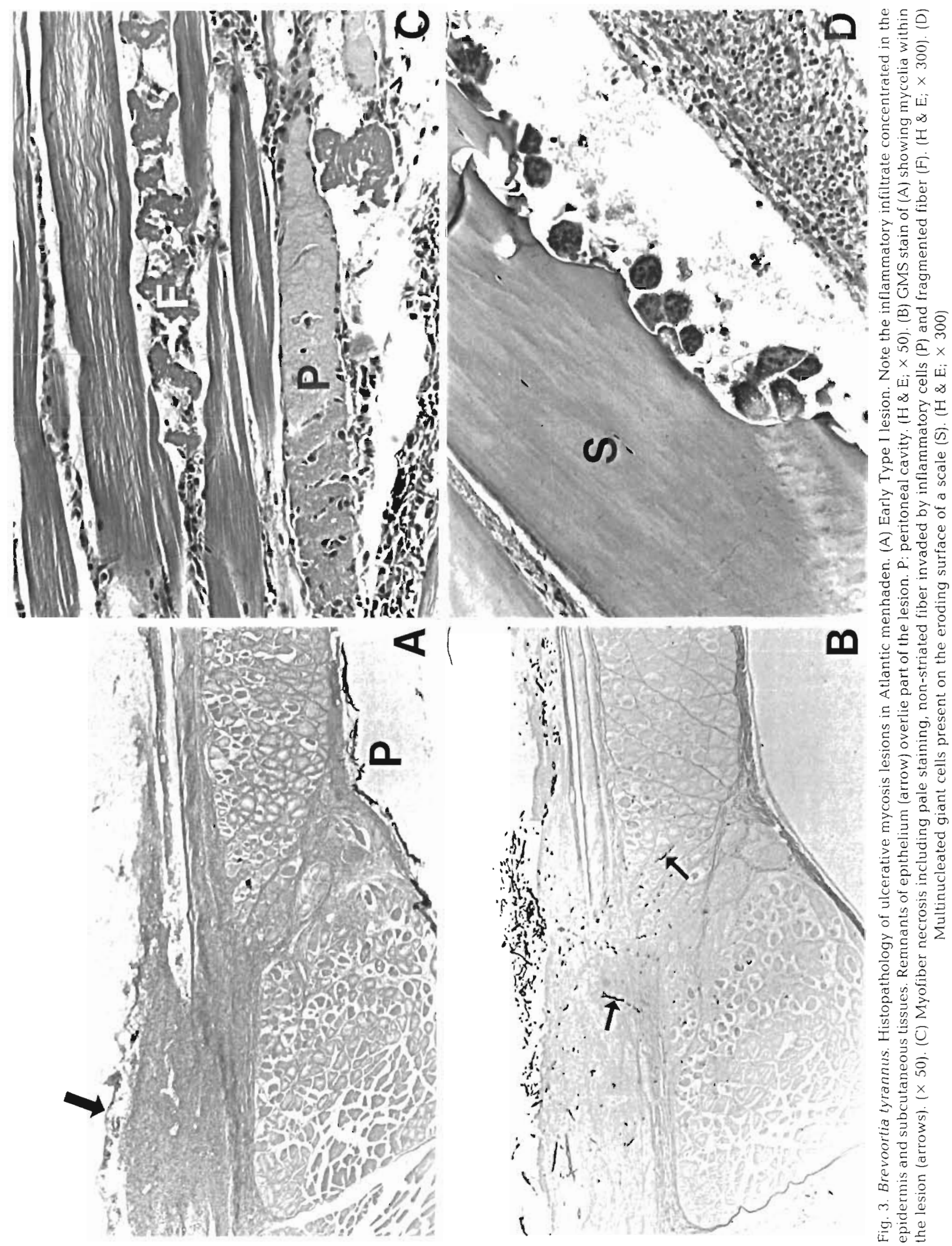



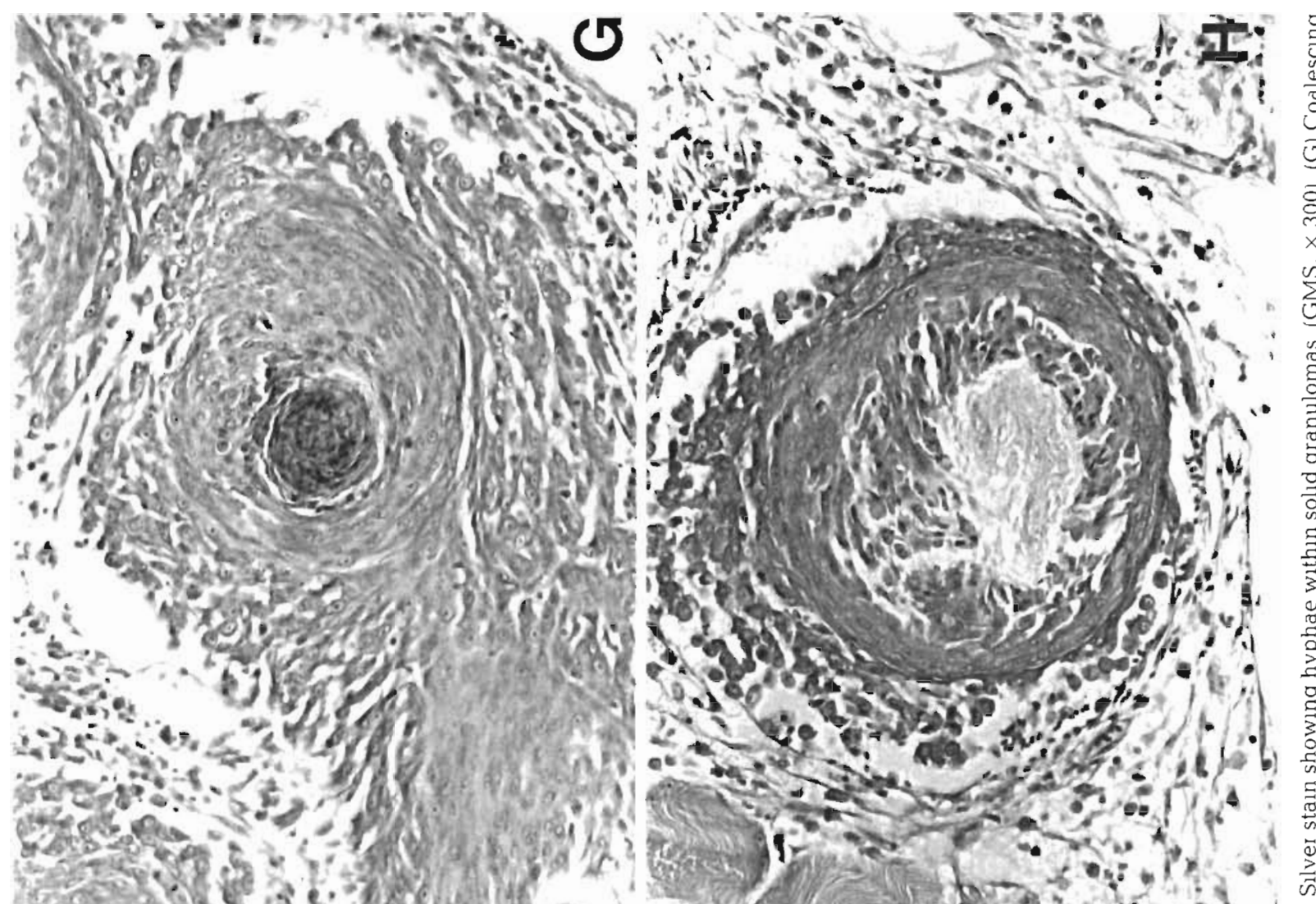

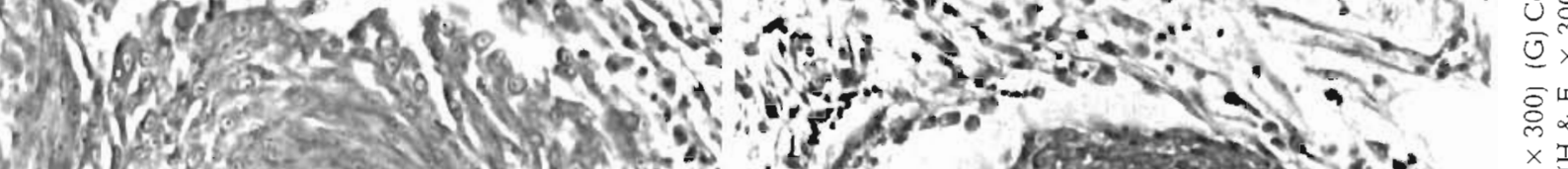

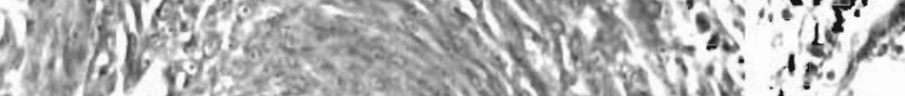
\%

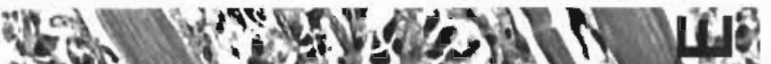

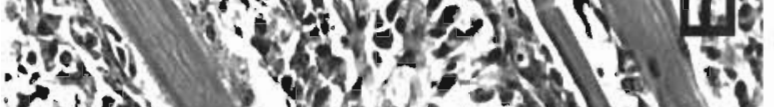

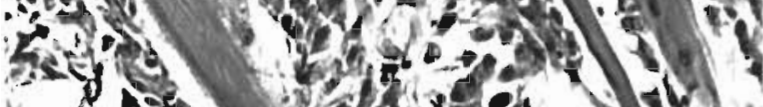
भing

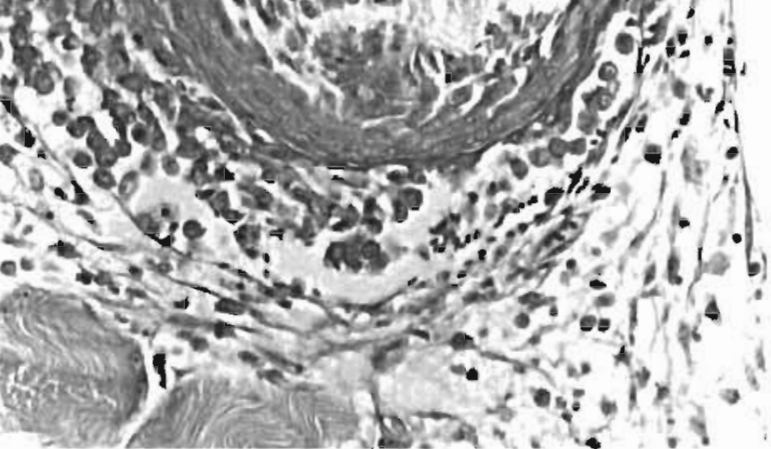
(a)

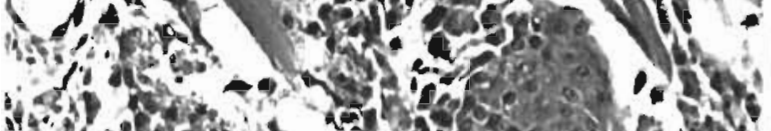
ing

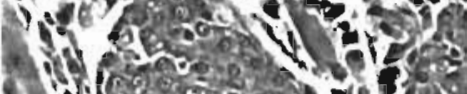

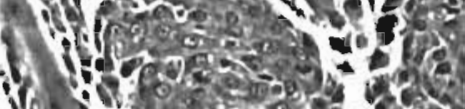

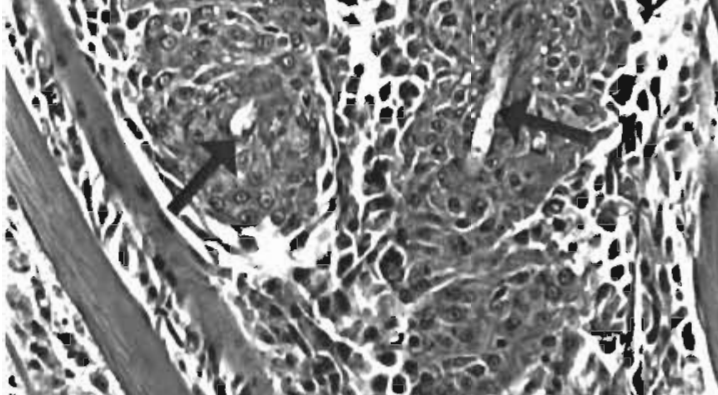

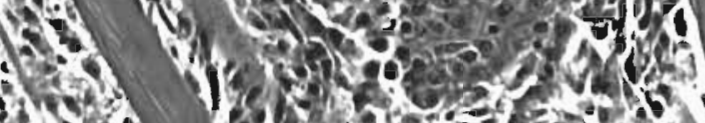

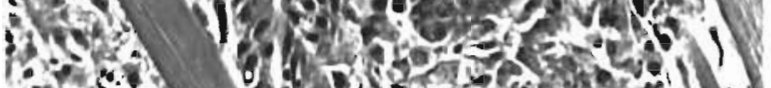

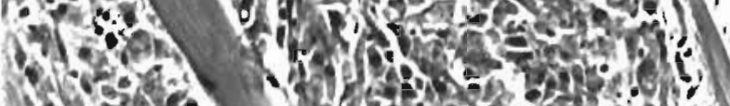
in

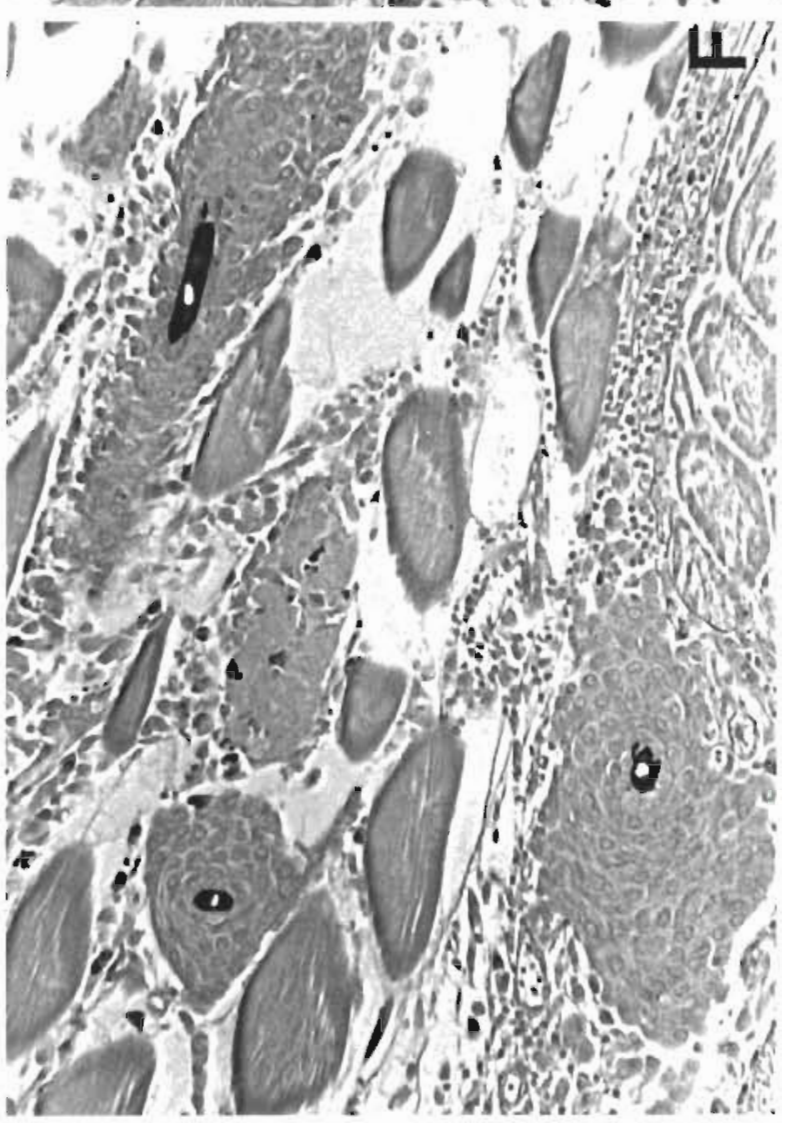
. 
intense granulomatous inflammation with large coalescing granulomas. One lesion consisted primarily of a single, large granuloma with a necrotic core. Some congestion, hemorrhage, and esoiniphilic granular cells were also present. Fungal hyphae were present, but many granulomas had only necrotic, amorphous debris (Fig. 3H)

Advanced. These lesions consisted of open ulcers up to $25 \mathrm{~mm}$ in diameter that contained white, friable material consisting of numerous hyphae interspersed within necrotic muscle. The tissue was edematous and the necrotic mass often protruded from the body (Fig. $2 C)$. The fungal hyphae were surrounded by an intense granulomatous inflammation with many granulomas. Granulomas often had deeply basophilic, necrotic centers (Fig. 3G). Some iesions aiso had a iymphocytic infiltrate, hemorrhage, congestion and/or eosinophilic granular cells. Foreign-body-type multinucleated giant cells were seen occasionally. Hyphae often extended beyond the zone of inflammation, and isolated muscle fiber necrosis (loss of striations, fragmentation, and myophagia) was often present in fibers without associated hyphae (Fig. 3C). Ultrastructural examination of muscle fibers in various stages of degeneration did not reveal viruses or other microbial pathogens.

Advanced lesions extended deep into the body and thus often involved adjacent internal organs. Lesions overlying the peritoneal cavity almost invariably affected the viscera by extension. Liver, intestine, gonads, pancreas, spleen, kidney, and spinal cord could all be infected by hyphae, often with resulting inflammatory adhesions. Occasionally, lesions that began on one flank extended through the body to the other flank. A mycotic fin rot that eroded the caudal fin was occasionally seen. Opercular erosion was also occasionally seen (Fig. 2F). Gram-negative bacterial rods were visible in some lesions; FF and $G$ stains did not reveal other pathogens.

End-stage lesion. These lesions became increasingly common as an outbreak subsided. The necrotic core of fungus-infected tissue was sloughed, leaving a cratershaped cavity that was surrounded by dark red to white, relatively smooth muscle tissue. These lesions had a non-swollen (non-edematous) periphery (Fig. 2D). While many contained large numbers of hyphae. some ulcers had primarily a lymphocytic infiltrate associated with numerous Gram-negative rods that were especially concentrated on the surface of the ulcers. Most lesions with heavy bacterial infections had large areas of necrotic cell debris. Multinucleated giant cells were rarely present. Bone remodeling and osteoblastic activity were seen in some lesions. Some lesions had mild fibroplasia. One lesion had many goldencolored GMS-positive melanomacrophages, both solitary and in aggregates.
Healing lesion. These lesions were relatively uncommon and small, usually less than $5 \mathrm{~mm}$ in diameter. They appeared as smooth, nonulcerated areas of tissue loss; lesions overlying the peritoneal cavity (the most common site of healing lesions) were black due to the presence of melanocytes lining the peritoneum (Fig. $2 \mathrm{E})$. In these cases, the peritoneal lining was continuous with the outer body wall. The epidermis was intact and mildly hyperplastic; occasional regenerating scales were observed. Mild to moderate granulomatous inflammation was present; most granulomas had only eosinophilic, GMS-positive, amorphous debris (Fig. $3 \mathrm{H})$. Few hyphae were present. The muscle tissue was replaced by fibrous connective tissue and fat; visceral adhesions were common.

\section{Other lesions}

We observed some changes in internal organs; however, none appeared to be associated with skin ulcess and there were no pathological changes consistently seen in all affected fish. Digenea were occasionally present in the intestinal lumen. Small isolated granulomas were commonly seen in the intestine, mesentery, and kidney; these lesions had no fungi detectable by GMS. The kidney in some fish had apparently damaged glomeruli, characterized by the release of protein into Bowman's space, and, in 1 fish, by the presence of hyaline droplets in the tubular epithelium. Some fish had hyperchromatic hepatic foci. Almost all fish had mild branchial hyperplasia and, rarely, telangiectasis. The myxosporean Kudoa was frequently seen in muscle; this parasite did not induce an inflammatory response. All of the 'other' lesions were also seen to the same degree in clinically normal fish.

\section{DISCUSSION}

Our data suggest that UM probably begins as a skin infection that progresses to involve underlying muscle and viscera. There was no evidence for a hematogenous or other method of dissemination throughout the body. The consistent presence of fungus in the smallest detectable lesions suggests that it plays a prime role in initiating the infection. Studies are presently underway to determine if experimental infection with the fungus can reproduce the disease.

The anal area was an extremely common site of the infection. Richards \& Pickering (1978) also found common sites for Saprolegnia infections of wild brown trout: lesions were more commonly located on the dorsum in mature males and on the caudal fin in mature females. These differences were at least partly 
attributed to trauma from spawning activity. Menhaden are pelagic schooling fish and we have never seen them exhibit intraspecific aggression in culture. However, damage due to predator attacks or parasite feeding cannot be ruled out. Site-specific differences in local immunity (goblet cell density, epithelial thickness, etc.) may also be important. Finally, it is possible that zoospores (the motile stage generally considered the normal means for transmission of Oomycetes) may be stimulated to attach in the anal area due to the release of nutrients or other chemoattractants from the intestinal tract. Fish-pathogenic isolates of Saprolegnia have been shown to encyst and germinate in low nutrient concentrations that do not stimulate germination in non-pathogenic species (Willoughby et al. 1983). Thus, a low level concentration gradient in this area may stimulate differentiation of water-borne spores.

Our observations of UM in the field suggest that the disease progresses very rapidly. During outbreaks, small lesions were uncommon. Most fish had ulcers containing a large amount of edematous, friable tissue and hyphae. This necrotic material eventually sloughed, producing an end-stage lesion; at this stage, the ulcers appeared to stop enlarging. Wet mounts of hyphae in these end-stage lesions showed no cytoplasmic streaming; cytoplasmic streaming is characteristic of living Oomycetes. Hyphae also exhibited prominent Brownian motion, indicating that they were dead. This was also commonly observed in advanced lesions. Both advanced and end-stage lesions had large numbers of bacteria (Noga \& Dykstra 1986). While the importance of bacteria in initiating UM is uncertain, they may have an important influence on the outcome of the disease. Bacteria can rapidly outcompete oomycete fungi, especially Aphanomyces sp. In vitro studies using menhaden muscle tissue explants have shown that an Aphanomyces sp. isolated from menhaden ulcers grows vigorously on sterile muscle tissue but is severely inhibited if bacteria are present (Noga \& Dykstra unpubl.). Thus, once lesions become heavily contaminated with bacteria, the fungi may be killed and thus lesion development may be arrested.

Although many fish with end-stage lesions were observed, there were very few fish with healing lesions. All healing lesions were smaller than the typical advanced or end-stage lesions, suggesting that only fish with small lesions can survive. Both these findings suggest that few fish can recover from UM, even if the progress of the disease has been arrested. The considerable osmotic stress associated with the large ulcers probably causes severe fluid imbalance. Richards \& Pickering (1979) found that Saprolegnia infection of the skin was sufficient to cause death due to osmotic shock in brown trout Salmo trutta L. The severe organ damage that is associated with lesions that penetrate into the peritoneal cavity undoubtedly exacerbates this stress. The large numbers of bacteria present may also contribute to morbidity. We have shown that some fish have bacteremias (Noga \& Dykstra 1986). Such very sick fish may also be more susceptible to predation.

Muscle damage often extended beyond the site of inflammation or fungal growth. This may have been due to osmotic damage from exposure of the muscle to water; however, this cannot explain why fibers deep within the lesion were often affected, while more normal fibers were often seen near the surface of the lesions. Another possible reason for this damage is the release of lytic enzymes or other toxins by the fungi. Peduzzi \& Bizzozero (1977) suggested that proteolytic enzyme activity could allow certain Saprolegnia species to convert from a saprophytic form of existence to one that feeds on fish tissue. Enzymes and other toxins are also commonly present in plant-pathogenic fungi (Buttrell 1974). Finally, these fungi may stimulate the activation or release of inflammatory mediators that, in addition to providing protection against these pathogens, may also damage host tissues. Numerous non-specific factors, such as C-reactive protein and complement, have been shown to be present in fish serum (Ellis 1981). Such factors have the capacity to damage host tissues as well as microbes.

Fungal granulomas are the hallmark of UM infection, being present from the smallest detectable lesion up until apparent healing occurs. The stage of lesion development could be inferred from the maturity of the granulomas. Typically, granulomas in early lesions were small, solid nodules. As lesions enlarged and the inflammatory response intensified, many granulomas developed necrotic centers; in the most mature stage observed (i.e. healing), 'cystic' granulomas containing only remnants of mycelia were predominant. This chronological sequence of granuloma differentiation corresponds to that described previously in granulomatous lesions resulting from experimental (Balouet \& Baudin-Laurencin 1986) and natural (Agius 1978, Majeed at al. 1981) diseases

Type II early lesions had features of mature lesions. These included many granulomas with necrotic or cystic centers. This suggests that such lesions may represent an arrested state of UM development. We suspect that lesions normally ulcerate rapidly. This conclusion would be consistent with our clinical findings. Why Type II early lesions may have an inhibited development is unknown, but the host's immune status may be an important determinant since the fungus is in very intimate contact with host tissues during its growth.

The pathogenesis of UM in menhaden is unusual for oomycete infections of fish, which typically produce superficial, cottony growths on the surface of the skin 
(Wolke 1975, Richards 1978). The only other published report of a granulomatous oomycete infection in fish is mycotic granulomatosis (MG), a disease of treshwater fish caused by a fungus that has been referred to as Aphanomyces piscida (Miyazaki \& Egusa 1972, Hatai et al. 1984). This disease is very similar to UM. It reportedly begins as a scale pocket infection that spreads locally to form a large, crater-shaped ulcer. Internal organs are commonly affected by extension of skin lesions. The progression of the inflammatory response is virtually identical to our observations in Atlantic menhaden. Early lesions have primarily a mononuclear infiltrate that leads to well-developed, epithelioid granulomas in advanced lesions. Older lesions are often heavily infected with bacteria.

As with UM, MG lesions often have multinucleated giant cells (Miyazaki \& Egusa 1972, Miyazaki \& Egusa 1973). Miyazaki \& Egusa (1972) defined 2 types of giant cells. Giant cells with engulfed hyphae were always within the granulomas of muscle tissue, while giant cells without hyphae usually appeared in the loose connective tissue of the dermis or lamina propria, or in contact with a scale. Giant cells appear to be common in fungal granulomas of fish (Richards et al. 1978). However, we noticed that the giant cells in UM lesions were usually closely associated with bone remodeling activity (Fig. 3D); this raises the question of whether all of these cells are typical inflammatory cells or instead whether some may be osteoclasts.

Ulcerative mycosis was first recognized in Atlantic menhaden in 1984 (Hargis 1985). However, in 1971 Kroger \& Guthrie (1972) observed both Atlantic and Gulf menhaden Brevoortia patronus with ulcerations that appeared very similar to UM lesions. These fish were not necropsied and, at the time, the lesions were attributed to attacks by predatory fish. Coincidentally, local fishermen initially considered predatory attacks to be responsible for UM lesions in Pamlico River menhaden.

A number of other skin diseases affect menhaden in the Pamlico River estuary. These lesions can look grossly similar to UM. We have seen lesions associated with copepod infections and apparently bacterial infections in some fish. However, these lesions are uncommon compared to UM. Differential diagnosis is based on the presence of deep ulcers containing broad aseptate hyphae with granulomatous inflammation. It is important to distinguish these skin lesions from UM because the risk factors associated with their development may be very different.

Acknowledgements. We thank J. Reid and D. Moye for technical assistance, and J. Wright and $M$. Levy for helpful discussions. This work was supported by NOAA Office of Sea Grant \# 83-AA-D-0012, The University of North Carolina Water
Resources Research Institute Grant \# 70054, the North Carolina Department of Administration, and the North Carolina Division of Marine Fisheries.

\section{LITERATURE CITED}

Agius, C. (1978). Infection by an IChthyophonus-like fungus in the deep sea scabbard fish Aphanopus carbo (Lowe) (Trichuridae) in the North East Atlantic. J. Fish Dis. 1 191-193

Balouet, G., Baudin-Laurencin, F. (1986). Granulomatous nodules in fish: an experimental assessment in rainbow trout, Salmo gairdneri Richardson, and turbot, Scophthalmus maximus (L.). J. Fish Dis. 9: 417-429

Buttrell, E. S. (1974). Parasitism of fungi on vascular plants Mycologiá 66: 1-15

Dykstra, M. J., Noga, E. J., Levine, J. F., Moye, D. F., Hawkins, J. H. (1986). Characterization of the Aphanomyces species involved with ulcerative mycosis in menhaden, Brevoortia tyrannus. Mycologia 78: 664-672

Ellis, A. E. (1981). Nonspecific defense mechanisms and their role in disease processes. Dev. Biol. Standard. 49: 337-352

Grier, H. W., Quintero, I. (1987). A microscopic study of ulcerated fish in Florida. Final Rep. WM-164, Florida Bureau of Marine Research, St Petersburg, Florida

Hargis, W. J. (1985). Quantitative effects of marine diseases on fish and shellfish populations. Trans. North Am. Wildl Nat. Resour Conf. 50: 608-640

Hatai, K., Takahashi, S., Egusa, S. (1984). Studies on the pathogenic fungus of mycotic granulomatosis. IV Changes of blood constituents in ayu Plecoglossus altivelis, experimentally infected and normally infected with Aphanomyces piscida. Fish Pathol. 19: 17-23 (Japanese)

Kroger, R. L., Guthrie, J. F. (1972). Effect of predators on juvenile menhaden in clear and turbid estuaries. Mar. Fish. Rev. 34: 78-80

Majeed, S. K., Gopinath, C., Jolly, D. W. (1981), Pathology of spontaneous tuberculosis and pseudo-tuberculosis in fish. J. Fish Dis. 4: 507-512

McDowell, E. M., Trump, B. F. (1976). Histologic fixatives suitable for diagnostic light and electron microscopy. Arch Pathol. Lab. Med. 100: 405--414

Miyazaki, T., Egusa, S. (1972). Studies on mycotic granulomatosis in fresh-water fishes. I. The goldfish. Fish Pathol. 7: 15-25. (Japanese)

Miyazaki, T., Egusa, S. (1973). Studies on mycotic granulomatosis in fresh-water fishes. II. Ayu Plecoglossus altivelis. Fish Pathol. 7: 124-133. (Japanese)

Noga, E. J., Dykstra، M. J. (1986). Oomycete fungi associated with ulcerative mycosis in menhaden, Brevoortia tyrannus (Latrobe). J. Fish Dis. 9: 47-53

Peduzzi, R., Bizzozero, S. (1977). Immunological investigation of four Saprolegnia species with parasitic aclivity in fish: serological and kinetic characterization of a chymotrypsinlike activity. Microb. Ecol. 3: 107-118

Ruchards, R. H. (1.978). The mycology of teleosts. In: Roberts R. J. (ed.) Fish pathology. Bailliere-Tindall, London, p. 205-215

Richards, R. H., Hollimàn, A., Helgason, S. (1978). Exophiala salmonis infection in Atlantic salmon Salmo salar L. J. Fish Dis. $1: 357-368$

Richards, R. H., Pickering, A. D. (1978). Frequency and distribution patterns of Saprolegnid infection in wild and 
hatchery-reared brown trout Salmo trutta L. and char Salvelinus alpinus (L.). J. Fish Dis. 1: 69-82

Richards, R. H., Pickering, A. D. (1979). Changes in serum parameters of Saprolegnia-infected brown trout, Salmo trutta L. J. Fish Dis. 2: 197-206

Willoughby, L. G., McGrory, C. B., Pickering, A. D. (1983).
Zoospore germination of Saprolegnia pathogenic to fish. Trans. Br. Mycol. Soc. 80: 421-435

Wolke, R. E. (1975). Pathology of bacterial and fungal diseases affecting fish. In: Ribelin, W E., Migaki, G. (eds.) The pathology of fishes. University of Wisconsin Press, Madison, p. 33-116

Responsible Subject Editor: Dr T Evelyn; accepted for printing on May 10, 1988 